\title{
Gender differences in response to CRTD therapy in patients with valvular regurgitation
}

\author{
(D)Marija Mance ${ }^{1 *}$, \\ Divan Bitunjac², \\ (D)Richard Matasić', \\ DKristina Gašparović', \\ (D)Petra Lepetić ${ }^{3}$, \\ (DSandra Večerić', \\ (D)Martina Lovrić \\ Benčić'
}

'University of Zagreb School of Medicine, University Hospital Centre Zagreb, Zagreb, Croatia

${ }^{2}$ General Hospital "Dr. Josip Benčević", Slavonski Brod, Croatia

${ }^{3}$ University Hospital Centre "Sestre milosrdnice", Zagreb, Croatia

\section{RECEIVED:}

February 28, 2019

ACCEPTED:

March 24, 2019

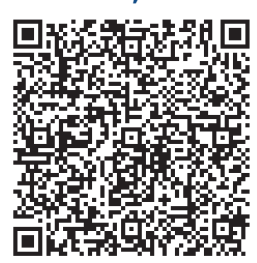

$\square$ Cardiologia Croatica 2019;14(3-4):98.

\begin{abstract}
KEYWORDS: cardiac resynchronization therapy, CRTD, valvular regurgitation CITATION: Cardiol Croat. 2019;14(3-4):98. | https://doi.org/10.15836/ccar2019.98
\end{abstract}

*ADDRESS FOR CORRESPONDENCE: Marija Mance, Klinički bolnički centar Zagreb, Kišpatićeva 12, HR-10000 Zagreb, Croatia. / Phone: +385-99-7742-627 / E-mail: marija.brestovac@gmail.com

ORCID: Marija Mance, https://orcid.org/0000-0003-1542-2890 • Ivan Bitunjac, https://orcid.org/0000-0002-4396-6628 Richard Matasic, https://orcid.org/0000-0003-1289-1704 • Kristina Gašparović, https://orcid.org/0000-0002-1191-4831 Petra Lepetić, https://orcid.org/0000-0003-0009-5217 • Sandra Večerić, https://orcid.org/0000-0002-8070-1012 Martina Lovrić Benčić, https://orcid.org/0000-0001-8446-6120

\section{||||||||||||||||||||||||||||||||||||||||||||||||||||||||||||||||||||||||||||||||||||||||||||||||||||||||||||||||||||||||||||||||||||||||}

Introduction: Patients with symptomatic chronic heart failure (sCHF) and implanted cardiac resynchronization device (CRTD) were included in this retrospective study in order to evaluate possible differences in mitral (MR) and tricuspid (TR) valvular regurgitation severity, NYHA class and left ventricle ejection fraction (LVEF) between male and female CRTD patients during follow up of 6 months after CRTD implantation.

Patients and Methods: We included 135 patients (89 men, 46 women) with sCHF due to any cause with implanted CRTD according to guidelines with optimal medical therapy regardless of atrial fibrillation or in sinus rhythm. Clinical (NYHA class) and echocardiographic data (valve pathology, LVEF) were assessed before and 6 months after CRTD implantation. Using color and continuous wave Doppler, PISA, regurgitation volume and vena contracta measurements, mitral regurgitation (MR) and tricuspid regurgitation (TR) were stratified in 3 grades. Echocardiography was recorded always by the same echo-technician to avoid inter-observer variability.

Results: Mean age of patients was $60( \pm 10)$ years. The results showed improvement in LVEF from $25 \%$ up to $36 \%$ ( $p=0.006)$ in all patients regardless of sex and age, as well as worsening of TR $(p<0.001)$ and no difference in MR ( $p=0.195)$. In male patients $(N=89)$, significant worsening in MR and TR was present $(p<0.05)$ while there was no significant worsening in MR $(p=0.42)$ nor TR $(p=0.06)$ in female patients $(\mathrm{N}=46)$. In patients older than 60 years $(\mathrm{N}=82$, female $27(33 \%)$, male $55(67 \%))$, as well as younger than 60 years ( $\mathrm{N}=53$; female $19(36 \%)$, male $34(64 \%))$ significant worsening of TR grade was observed $(\mathrm{p}<0.05)$, while the grade of MR remained the same $(\mathrm{p}=0.255$ and $\mathrm{p}=0.534)$. An improvement in NYHA class was observed in 75 patients (71\%), no change in 25 patients (24\%) and worsening in 5 patients (5\%). Overall improvement in NYHA class was statistically significant $(\mathrm{p}<0.001)$.

Conclusion: Six months after CRTD implantation the severity of MR and TR remained the same in female patients while significant worsening of MR and TR severity was found in male patients. TR worsening might be due to implanted electrodes. The age of patients had no impact on LVEF, TR and MR change. Despite improvement in clinical status and NYHA class, the echocardiography results did not meet our expectations..$^{1-4}$ Due to limited number of patients the results were not divided according to the etiology of CHF.

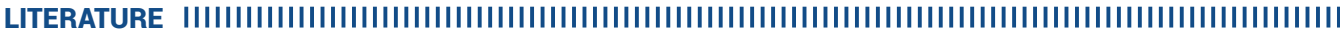

1. Randolph TC, Hellkamp AS, Zeitler EP, Fonarow GC, Hernandez AF, Thomas KL, et al. Utilization of cardiac resynchronization therapy in eligible patients hospitalized for heart failure and its association with patient outcomes. Am Heart J. 2017 Jul;189:48-58. https://doi.org/10.1016/j.ahj.2017.04.001

2. Binda C, Menet A, Appert L, Ennezat PV, Delelis F, Castel AL, et al. Time course of secondary mitral regurgitation in patients with heart failure receiving cardiac resynchronization therapy: Impact on long-term outcome beyond left ventricular reverse remodelling. Arch Cardiovasc Dis. 2018 May:111(5):320-331. https://doi.org/10.1016/j.acvd.2017.05.009

3. Jin H, Yang S, Hua W, Gu M, Niu H, Ding L, et al. Significant mitral regurgitation as a predictor of long-term prognosis in patients receiving cardiac resynchronisation therapy. Kardiol Pol. 2018;76(6):987-992. https://doi.org/10.5603/KP.a2018.0035

4. Mediratta A, Addetia K, Yamat M, Moss JD, Nayak HM, Burke MC, et al. 3D echocardiographic location of implantable device leads and mechanism of associated tricuspid regurgitation. JACC Cardiovasc Imaging. 2014 Apr;7(4):337-47. https://doi.org/10.1016/j.jcmg.2013.11.007 